\title{
Exploiting paracrine mechanisms of tissue regeneration to repair damaged organs
}

\author{
Diana F Anthony and Paul G Shiels
}

\begin{abstract}
Stem cells have been studied for many years for their potential to repair damaged organs in the human body. Although many different mechanisms have been suggested as to how stem cells may initiate and facilitate repair processes, much remains unknown. Recently, there has been considerable interest in the idea that stem cells may exert their effects in vivo via paracrine actions. This could involve the release of cytokines, growth factors or secreted extracellular vesicles. This article reviews the role that paracrine actions may play in tissue regeneration. In particular, it considers how microvesicles, as a mediator or modulator of paracrine action, can be exploited as a tool for non-cell-based therapies in regenerative medicine.
\end{abstract}

Keywords: Stem cells, Paracrine action, Tissue and cell regeneration, Microvesicles

\section{Introduction}

The potentially advantageous effects of using stem cells in tissue regeneration were first demonstrated by Till and McCulloch in the 1960s [1,2]. This pivotal discovery paved the way for regenerative medicine, which in the last decade has advanced significantly. Regenerative medicine is broadly defined as the study of the repair, replacement, regeneration and restoration of diseased, damaged or aged cells, tissues or organs [3,4]. It has emerged as a serious solution to the repair of end-stage organ damage and to address the growing shortfall in donor organs for transplantation. Its clinical use is still very much in its infancy and much remains to be determined about the mechanisms of action for cellular therapeutics. In this review, we will attempt to summarise some of the current state-of-the-art information available in this field, with an emphasis on mesenchymal stem cells and other non-embryo-derived cellular therapies, which are advancing rapidly towards the clinic, with special reference to paracrine-mediated tissue repair.

The first successful demonstration of regenerative medicine, using a cell-based therapy to repair damaged tissue, was described by Ferrari et al. [5]. This group

\footnotetext{
*Correspondence: Paul.Shiels@glasgow.ac.uk Department of Surgery, Institute of Cancer Sciences, College of Medical, Veterinary and Life Sciences, University of Glasgow, Western Infirmary, Glasgow G11 6NT, UK
}

showed that regeneration of damaged muscle fibres was possible by transplanting bone marrow stem cells into injured muscle tissue [5]. Subsequently, a variety of different stem cell types has been isolated and investigated for use in tissue regeneration, with varying degrees of success. These include mesenchymal stem cells (MSCs) [6-9], adipose-derived stem cells (ASCs), also known as adipose-derived MSCs [10], embryonic stem cells (ESCs) [11], endothelial progenitor cells (EPCs) [12] and cardiac stem cells (CSCs) [13] (see Figure 1 for general properties of stem cells). Amongst the many choices available at present, MSCs have been the most favoured for the majority of published studies. MSCs are primarily isolated from the bone marrow, but they can also be derived from other tissue sources. Their popularity with researchers lies in a number of inherently advantageous properties, including easily identifiable cell surface markers, their adhesiveness to plastic facilitating culture ex vivo and their ability to differentiate into multiple cell lineages. Moreover, they can be sourced from an adult; hence, they are free from the ethical issues around research using ESCs [6]. More recently, pathfinder cells (PCs), a novel cell population named for their ability to navigate a path towards the site of damaged tissues in vivo, have been described [14-17].

Although there has been a great deal of discussion about how stem cells contribute to the regeneration of damaged tissues, much remains to be understood. One 


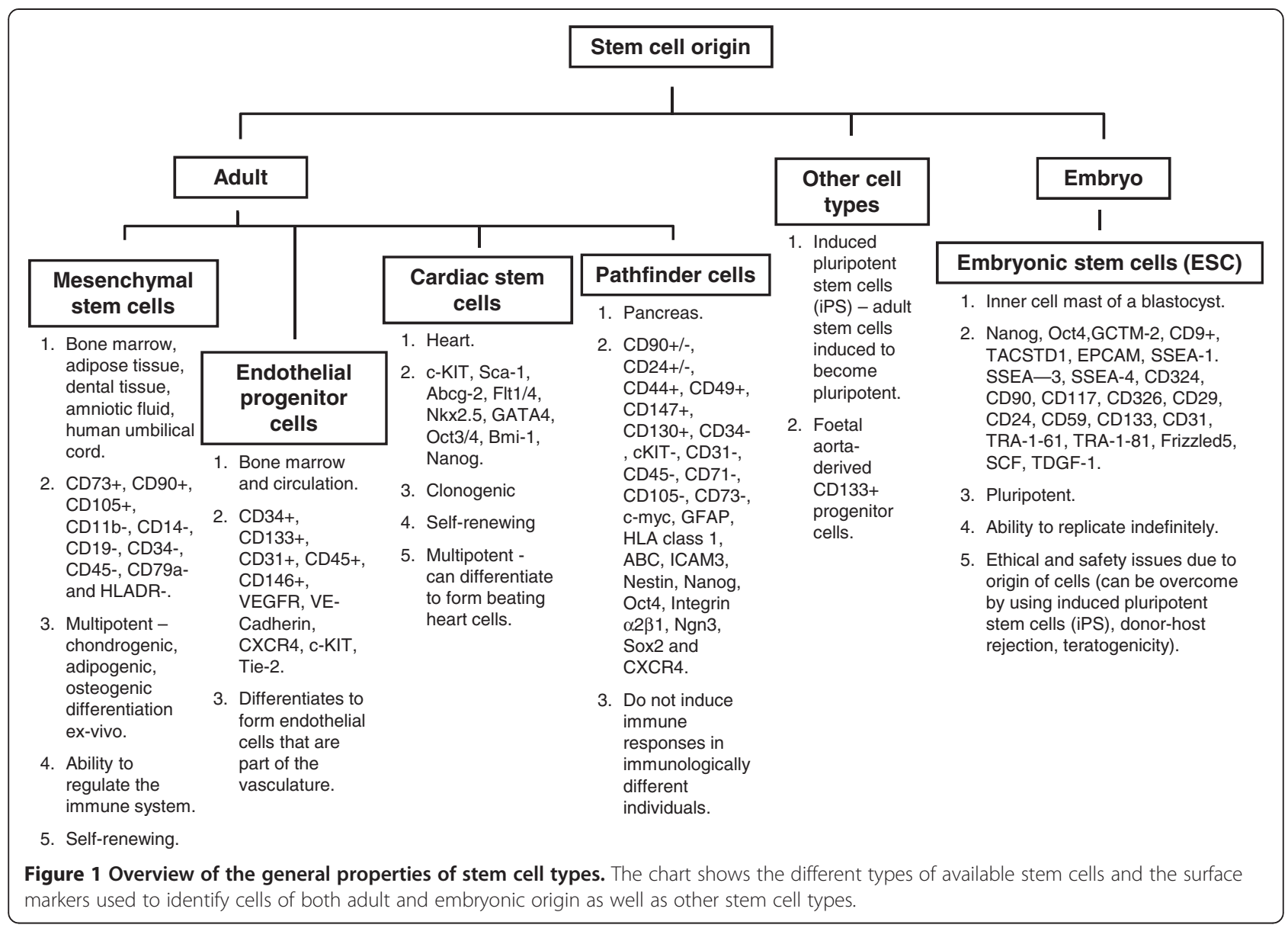

mechanism by which stem cells might repair damaged tissue is by means of differentiation of the stem cells into tissue-specific cell types $[18,19]$. Others have suggested that stem cells fuse with host cells in order to replace damaged tissue $[20,21]$. A more recent suggestion is that these cells work via paracrine signalling, instead of direct differentiation or fusion between cells. Paracrine signalling may act to stimulate damaged target cells to proliferate [22] or may induce other local cell types to differentiate [16]. The purpose of this review article is to provide an overview of the role that paracrine factors may play in various tissue damage models and how we can exploit this for the future treatment of disease.

\section{Paracrine action of stem cells in disease models}

The idea that stem cells work via a paracrine action is now more widely accepted. Understanding paracrine signalling by cells involved in the repair of damaged tissue is important to the implementation of any future regenerative therapies. Paracrine signalling is defined as a form of communication between two different cells, where one cell releases chemical mediators to its immediate environment, which results in a change in the behaviour of a cell in its adjacent environment. There are numerous suggestions as to how the paracrine effects observed in many different model tissue repair systems are mediated. However, none has yet proven definitive.

The protective and regenerative effects of different stem cell therapies have been attributed to paracrine action in many cardiovascular studies. Coronary artery disease and heart failure are a leading cause of mortality and morbidity, particularly in the developed world. Consequently, many investigators have focused their efforts in this area of research. It has been proposed that paracrine effects contribute to the improvement of cardiac function following tissue insult and injury by modifying various factors such as inflammation, fibrosis, apoptosis, neovascularisation, contractility and cardiac repair [23].

A study that transplanted human cardiac progenitor cells (hCPCs) into a mouse model of myocardial infarction (MI), found that hCPCs isolated following transplantation using laser capture micro-dissection, had significantly increased expression of growth factors, such as vascular endothelial growth factor (VEGF), fibroblast growth factor 2 (FGF2) and connective tissue growth factor in vivo [24]. The transplanted hCPCs stained negatively for cardiac and endothelial differentiation markers, indicating that no differentiation of hCPCs had occurred [24]. Furthermore, 
MSCs and MSC-conditioned media enhanced cardiac excitation-contraction coupling [9]. The authors of this study suggested that this was solely mediated via a paracrine mechanism, attributed to a phosphoinositide-3-kinase (PI3K)/Akt induced change in calcium signalling and an endothelial nitric oxide synthase (eNOS) mediated change in sarco-endoplasmic reticulum calcium transport ATPase (SERCA) activity, and not by inter-communication between the MSCs and cardiomyocytes.

Additionally, one group [25] demonstrated that incubation of cardiomyocytes subjected to hypoxia and reoxygenation with conditioned media from MSCs resulted in a cardio-protective effect. They suggested that this was due to a paracrine effect from the MSC-conditioned media, which protected the cells from damage by modulating the effect of a mitochondrial apoptotic pathway to reduce apoptosis via the inhibition of cytochrome $\mathrm{C}$ release from the mitochondria and by reducing activation of caspase-3 [25]. The protective effect of MSCs was also evident in a study using a rat model of pulmonary arterial hypertension (PAH). In this study [26], the authors demonstrated that sublingual vein injection of MSCs for two weeks resulted in improved lung and heart function following injury, improved pulmonary vascular remodelling, reduced inflammation and enhanced angiogenesis. These researchers suggested that these findings were possibly the result of a paracrine mechanism via secretion of anti-inflammatory mediators, as they observed reduced expression of inflammatory mediators, such as IL-1 $\beta$, IL-6, TNF- $\alpha$ and matrix metallopeptidase-9 (MMP-9), but higher levels of VEGF, in their MSC-treated group compared to untreated groups [26].

Recently published work [27] has suggested a potential role for microRNAs in cardiac regeneration effects. These researchers found that adult rat cardiomyocytes with limited capacity for differentiation can be induced to enter the cell cycle and proliferate by the exogenous administration of microRNAs, hsa-mir-590 and hsa-miR-199a, in both in vivo and in vitro experimentation [27]. MicroRNAs are small RNAs of approximately 21 to 25 nucleotides that negatively regulate gene expression post-transcriptionally and which can affect the function of diverse biological processes [28]. MicroRNAs have been shown to be released by cells in small vesicles, such as microvesicles and exosomes, which will be discussed in more detail below.

The use of stem cells, particularly MSCs, in recovery from acute kidney injury (AKI) has also been extensively studied. Ischaemia/reperfusion (I/R) injury is known to cause delayed cellular regeneration and functional recovery following kidney transplantation [29]. It has been suggested that the reno-protective effect of administered MSCs in rats with I/R AKI was mediated primarily by the paracrine action of MSCs [30]. Significantly, these investigators found: (i) increased secretion of growth factors and upregulation of cytokines such as hepatocyte growth factor (HGF), VEGF, insulin-like growth factor-1 (IGF-1), IL-10, basic FGF, tumour growth factor alpha (TGF- $\alpha$ ) and B-cell lymphoma-2 (Bcl-2), which are antiinflammatory, anti-apoptotic and known to improve renal function; (ii) downregulation of pro-inflammatory mediators such as IL- $1 \beta$, TNF- $\alpha$, IFN- $\gamma$ and inducible nitric oxide synthase (iNOS) and (iii) little to no intrarenal trans-differentiation events of administered MSCs [30]. Furthermore, they also demonstrated in a second study that MSC-conditioned media increased cell survival and the proliferation rate of endothelial cells in vitro and proposed that the vasculo-protective effect of MSCs was due to their ability to interact with endothelial cells by complex paracrine actions, which are able to protect and regenerate damaged vasculature in AKI significantly [7].

Wound healing is another area of research in which the possible effects of paracrine signalling by stem cells have been explored. Impairment of normal woundhealing processes often occurs in diabetic patients, leading to chronic wounds. These do not heal and can subsequently become gangrenous lesions or diabetic ulcers, often requiring the need for amputation. Thus, advancement of any regenerative therapy to repair such wounds and to promote fast healing would be beneficial. However, balance is needed between promoting fast wound healing and the formation of fibrous scar tissue, which could impair the function of the healed tissue or have a poor cosmetic appearance. One study [31] found that MSC-conditioned media accelerate wound-healing processes. Further investigations revealed that the medium contained high levels of growth factors and chemokines known to promote wound-healing. These included epidermal growth factor (EGF), keratinocyte growth factor (KGF), IGF-1, VEGF- $\alpha$, erythropoietin (EPO), stromal cell-derived factor 1 (SDF-1), macrophage inflammatory protein (MIP)-1a and MIP-1b, suggesting that MSCs may work by a paracrine mechanism to accelerate wound healing [31]. MSCs have also been shown to release anti-fibrotic cytokines, which reduce the formation of scar tissue [32]. It has been suggested that foetal aorta-derived $\mathrm{CD} 133^{+}$progenitor cells (and a conditioned medium from their culture) also act similarly in a model of ischaemic diabeticinduced ulceration [33]. These researchers found that $\mathrm{CD} 33^{+}$cells accelerated wound closure and promoted angiogenesis via a paracrine effect through the release of cytokines, which affect the Wnt pathway, leading to stimulation of endothelial cell proliferation, migration and survival [33]. More recently, adipose-derived MSCs have also been used to demonstrate this effect in cutaneous wound healing [34]. 
The effect of paracrine secretion by stem cells has also been noted in experiments using MSCs to induce repair processes in spinal cord injury in rats [35]. Even after 21 days of observations, the MSCs had not directly become incorporated into the regenerated host tissue, though there was a significant improvement in functional recovery from as early as a week after MSC treatment, suggesting an MSC-mediated paracrine effect [35]. The use of MSCs in spinal cord injury has been extensively reviewed elsewhere by Wright et al. [36].

Recently, a study [16] showed regeneration of damaged adult pancreatic tissue and complete long-term functional recovery using a xeno-transplant model, whereby streptozotocin-induced diabetic mice were injected with rat or human PCs. PCs are a novel adult cell type, lacking the standard MSC markers CD105 and CD73 [15]. Crucially, the regenerated pancreatic tissue was not a result of the trans-differentiation of rat or human PCs into fully functional mouse pancreatic islets [16]. Instead, it was proposed that the recovery observed was more likely the result of a paracrine signal from the PCs [16]. Notably, this effect was not observed with the use of a PCconditioned medium in this model, suggesting that it was not the result of cytokine or growth factor secretions, though this lack of efficacy might formally be due to a dose effect. PCs have subsequently been shown to repair renal damage resulting from ischaemic injury in a similar xeno-transplant model [17]. The low numbers of PCs or PC-derived cells found in the repaired kidney is again consistent with paracrine-mediated repair processes.

From the aforementioned experiments, it is evident that there is agreement amongst many researchers, tackling a diverse range of disease models, which clearly indicates the role that paracrine actions, as opposed to stem cell differentiation or cell fusion, have in repairing damaged tissues. Stem cells have been shown to target various local cells to exert their effects. For example, MSCs have been known to modulate the immune system by inducing immune cells, such as regulatory $\mathrm{T}$ cells, B-lymphocytes, natural killer (NK) cells and dendritic cells, and generating a regulatory phenotype of macrophages [37] while PCs affect pancreatic beta cells and are also immunomodulatory [16]. However, there still remains a need to further elucidate the precise mechanisms by which stem and progenitor cells initiate the repair of damaged tissues via paracrine actions. Aside from the observation that stem cells release a multitude of growth factors and cytokines to induce the reparative process, one exciting discovery is that these cells release microvesicles and exosomes, which may be a source of paracrine factors required for tissue repair and which may ultimately be used as therapeutic source material directly. Indeed, the recent discovery of a potential role for microRNAs, which occur in microvesicles and are one of the paracrine factors able to initiate repair processes in damaged cardiac tissue, adds another important dimension into the possibilities for therapeutic intervention [27].

\section{Microvesicles as mediators of paracrine effects}

One of the most rapidly emerging ideas that explain paracrine mechanisms of tissue regeneration is the use of stem cell-derived micro-secretory vesicles, which act as mediators of tissue regeneration following injury or disease. This is an exciting area of research, as it opens up the potential to explore non-cell-based therapy in regenerative medicine.

Micro-secretory vesicles include microvesicles, which are one of a number of membranous vesicles derived from cells that were previously thought of as artifactual, resulting from cell preparatory methods or from cellular debris without any specific biological purpose. Recent evidence, however, has shown that microvesicles possess the ability to participate and influence numerous biological processes [38]. It is now generally accepted that microvesicles could aid in the transfer of genetic information between cells, as they contain proteins, messenger RNAs (mRNAs), DNAs and/or microRNAs. They also regulate the physiology and pathophysiology of cells and can be exploited for therapeutic and diagnostic purposes [38-41]. Thus, microvesicles could be a useful tool to treat solid organ damage as they may act as mediators to promote anti-inflammatory, pro-angiogenic, antiapoptotic and differentiation or mitotic factors to activate the intrinsic repair and regeneration processes.

There remains controversy surrounding the nomenclature for micro-secretory vesicles such as microvesicles and exosomes, based on their size and their isolation methodologies. Whilst agreement needs to be reached on a standard definition for these vesicles, it is widely understood and accepted that both of these types of vesicle are structurally and morphologically distinct (Figure 2). A microvesicle arises from budding of the plasma membrane of a cell. Microvesicles are generally more heterogeneous in terms of size, which can range from anywhere between $100 \mathrm{~nm}$ and 1,000 nm. Conversely, exosomes are derived from an endocytosis process within cells and are more homogeneous with respect to vesicle size, ranging from $30 \mathrm{~nm}$ to $100 \mathrm{~nm}$ $[42,43]$. It has been suggested that microvesicles will sediment at a lower centrifugation speed compared to exosomes, which sediment at 100,000 $g$ [43]. Since most studies tend to sediment membranes at 100,000 $g$, any preparation will likely contain both microvesicles and exosomes, thus making it difficult to determine which of these contribute to the effects observed [43]. Furthermore, it should also be noted that most published research uses the term microvesicles to describe both of 


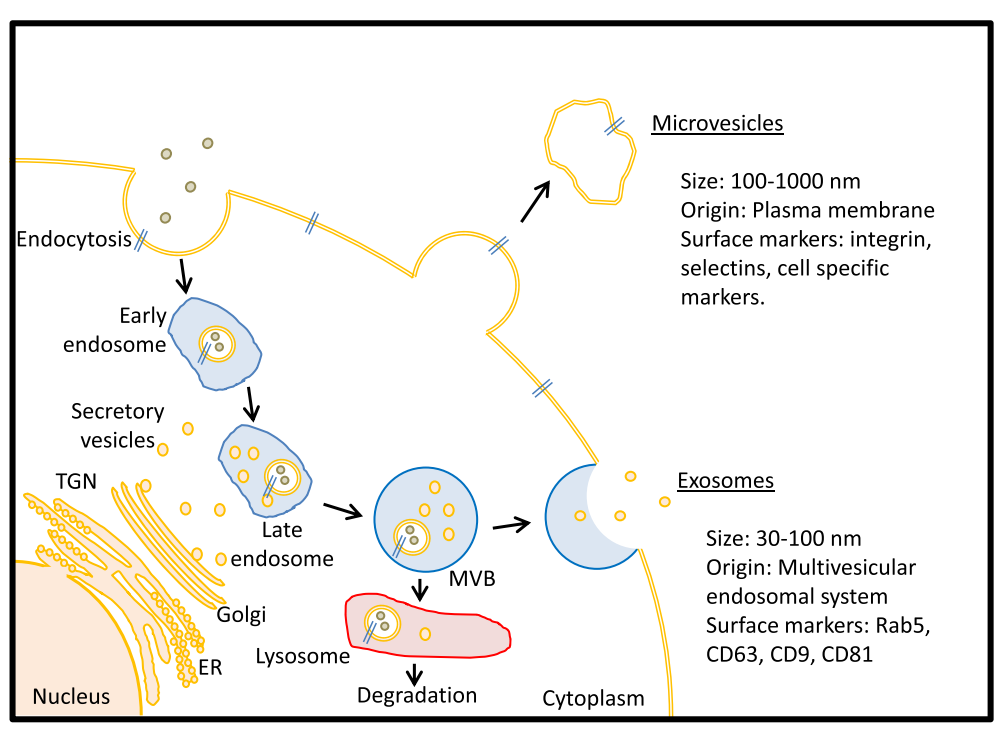

Figure 2 Origin of microvesicles and exosomes from cells. A microvesicle arises from budding of the plasma membrane. Microvesicles are more irregular in shape and size and can contain cytoplasmic materials. Microvesicles express surface markers such as integrin- $\beta$, CD 40 and selectins such as plasma selectins and/or proteins from the cells they originate from. Exosomes originate from the endosomal trafficking system and, therefore, are more regular in shape and size. Exosomes are more easily identifiable via cell surface markers such as CD81, CD9 and CD63 and may contain materials such as mitochondrial DNAs, mRNAs and miRNAs. ER: endoplasmic reticulum; miRNA: microRNA; TGN: trans-Golgi network; MVB: multi-vesicular bodies.

these types of micro-secretome. They are, however, distinct from apoptotic vesicles or bodies, which are shed from normal and diseased cells undergoing apoptosis [44].

Microvesicles derived from stem cells have already been shown to contribute to tissue and cellular regenerative processes. Microvesicles isolated from MSCs and EPCs have proliferative and anti-apoptotic effects on tubular epithelial and endothelial cells in vitro, in addition to being able to protect against AKI when delivered in vivo to a glycerol-induced severe combined immunodeficiency (SCID) mouse model [45] and to an I/R injury rat model $[46,47]$. This regenerative effect was also found to be specific for MSC- and EPCderived microvesicles, as it was not observed with fibroblast-derived microvesicles. Moreover, the effect was abolished when the MSC- and EPC-derived microvesicles were treated with RNase prior to use, suggesting that a form of RNA is a key player in their reparative function $[45,46]$.

This group of researchers also demonstrated the regenerative potential of microvesicles derived from human liver stem cells [48]. They showed the proliferative and anti-apoptotic properties of these human-derived microvesicles on human and rat hepatocytes in vitro and the regeneration and recovery of rat liver, when these microvesicles were administered into $70 \%$ hepatectomised rats [48]. They suggested that the microvesicles shuttle mRNAs involved in angiogenic pathways and microRNAs associated with cell proliferation, angiogenesis and inhibition of apoptosis, to the damage sites [45,46].

Additionally, recently published work [49] using microvesicles isolated from human umbilical cord MSCs, has demonstrated in vitro that microvesicles can be internalised by endothelial cells and promote the proliferation and angiogenesis of these cells in culture. Additionally, these researchers showed that this effect could be translated to in vivo experiments using a rat hind limb ischaemia model, whereby the exogenous microvesicles were found to be able to promote new blood vessel formation [49]. Further support for microvesicle/ exosome-mediated paracrine repair processes comes from observations of the administration of MSC-derived exosomes to a murine model of hypoxic pulmonary hypertension (HPH). This resulted in suppression of the inflammatory processes, which are known to be a damaging factor in the development of HPH [50].

The combined results from all these data, although at a very early stage, have been encouraging in furthering our understanding of how stem cells, and in particular microvesicles, function in the body to initiate tissue repair. These observations have provided a tantalising insight into the possible use of microvesicles as a future cell-free therapy for tissue repair.

\section{Potential future treatment for regenerative medicine}

Paracrine-mediated tissue repair might in future be exploited via genetic engineering of stem, progenitor or 
other cells to deliver various beneficial mediators to stimulate regenerative processes in damaged tissues. A number of researchers have looked at the potential of introducing beneficial factors by modifying stem cells to express these factors at the required level of efficacy. One such study [51] looked at using modified MSCs to express Wnt11; cardiomyocytes co-cultured with these MSCs had increased cell survival and reduced cell death following exposure to 40 hours of hypoxic conditions. In addition, MSC ${ }^{\text {Wnt11 }}$ cell infusion in vivo improved cardiac function in rats following MI, as well as reducing apoptosis and fibrosis in the damaged hearts [51]. The authors suggested that this was because the release of Wnt11 caused regeneration of the damaged hearts, as Wnt signalling has previously been reported to promote cardiomyogenic repair [51]. A similar study employing MSCs engineered to overexpress Akt also successfully showed, in vitro and in vivo, the cytoprotective effects of these engineered cells on ischaemic hearts [52].

Perhaps one of the more exciting novel therapeutic approaches is the development of non-cell-based therapies for studying the effects that microvesicles derived from various types of cells have on tissue regeneration. Microvesicles as a source for drug therapy can be made naturally, from either modified or unmodified regenerative cells, as mentioned previously. This possibility was demonstrated recently in an in vitro study [53] where MSCs were modified to express cystinosin, the gene for which (CTNS) is mutated in a rare disorder called cystinosis, which causes a large accumulation of cysteine in cells and eventually results in cellular apoptosis. It was found that microvesicles isolated from CTNSexpressing MSCs also contained CTNS mRNA and when incubated with CTNS mutant fibroblasts ${ }^{(-/-)}$, resulted in reduced cysteine accumulation in the cells [53]. Microvesicles may also be artificially manufactured to incorporate therapeutic entities for the treatment of a specific disease. This method may have certain advantages for the manufacturing processes and stringent quality control as well as because of the ability to design custom-made microvesicles that express proteins, mRNAs and/or microRNAs relevant to a particular disease or condition. Numerous ways in which microvesicles can be manipulated for use in regenerative medicine for organ and tissue regeneration and repair have been extensively reviewed by Ratajczak et al. [54].

\section{Conclusions}

Although many details of cellular paracrine effects remain to be elucidated, it is clear that the potential for the discovery of novel therapies for regenerative medicine will rise exponentially in the not too distant future and may ultimately result in such therapies being transferred from the lab into the clinic. Indeed, this development is already becoming a reality as currently two groups of researchers have started phase 1 clinical trials using cardiospherederived cells [55] and cardiac stem cells [56] to improve patient outcomes following an episode of MI. The full results of the trials are very much anticipated by the rest of the science and medical communities.

\section{Abbreviations}

AKI: Acute kidney injury; ASC: Adipose-derived stem cell; Bcl-2: B-cell lymphoma 2; CSC: Cardiac stem cell; EGF: Epidermal growth factor; eNOS: Endothelial nitric oxide synthase; EPC: Endothelial progenitor cell; EPO: Erythropoietin; ER: Endoplasmic reticulum; ESC: Embryonic stem cell; FGF2: Fibroblast growth factor 2; hCPC: Human cardiac progenitor cell; HGF: Hepatocyte growth factor; HPH: Hypoxic pulmonary hypertension; I/R: Ischaemia/reperfusion; IFN- $\gamma$ : Interferon gamma; IGF-1: Insulin-like growth factor 1; IL: Interleukin; iNOS: Inducible nitric oxide synthase; KGF: Keratinocyte growth factor; MI: Myocardial infarction; MIP: Macrophage inflammatory protein; miRNA: MicroRNA; MMP-9: Matrix metalloproteinase-9; MSC: Mesenchymal stem cell; NK: Natural killer; PAH: Pulmonary arterial hypertension; PC: Pathfinder cell; PI3K: Phosphoinositide-3-kinase; SCID: Severe combined immunodeficiency; SDF-1: Stromal cell-derived factor 1; SERCA: Sarco-endoplasmic reticulum calcium transport ATPase; TGF-a: Tumour growth factor alpha; TGN: Trans-Golgi network; TNF-a: Tumour necrosis factor alpha; VEGF: Vascular endothelial growth factor.

\section{Competing interests}

The authors declare that they have no competing interests.

\section{Authors' contributions}

DFA participated in the writing of the manuscript. PGS participated in its critical appraisal. Both authors read and approved the final manuscript.

\section{Acknowledgements}

The authors wish to thank Dr Alasdair McDonald for proofreading this article.

Received: 8 April 2013 Accepted: 13 June 2013

Published: 20 June 2013

\section{References}

1. Till JE, McCulloch EA: Direct measurement of the radiation sensitivity of normal mouse bone marrow cells. Radiat Res 1961, 14:213-222.

2. Becker AJ, McCulloch EA, Till JE: Cytological demonstration of the clonal nature of spleen colonies derived from transplanted mouse marrow cells. Nature 1963, 197:452-2.

3. Mironov V, Visconti RP, Markwald RR: What is regenerative medicine? Emergence of applied stem cell and developmental biology. Expert Opin Biol Ther 2004, 4:773-781.

4. Haseltine W: Regenerative medicine 2003: an overview. J Regen Med 2003, 4:15-18.

5. Ferrari G, Cusella-De Angelis G, Coletta M, Paolucci E, Stornaiuolo A, Cossu G, Mavilio F: Muscle regeneration by bone marrow-derived myogenic progenitors. Science 1998, 279:1528-1530.

6. Pittenger MF, Mackay AM, Beck SC, Jaiswal RK, Douglas R, Mosca JD, Moorman MA, Simonetti DW, Craig S, Marshak DR: Multilineage potential of adult human mesenchymal stem cells. Science 1999, 284:143-147.

7. Tögel F, Weiss K, Yang Y, Hu Z, Zhang P, Westenfelder C: Vasculotropic, paracrine actions of infused mesenchymal stem cells are important to the recovery from acute kidney injury. Am J Physiol Renal Physiol 2007, 292:F1626-F1635.

8. Chen JS, Wong W, Gurtner GC: Therapeutic potential of bone marrow-derived mesenchymal stem cells for cutaneous wound healing. Front Immuno 2012, 3:1-9.

9. DeSantiago J, Bare DJ, Semenov I, Minshall RD, Greenen DL, Wolska BM, Banach K: Excitation-contraction coupling in ventricular myocytes is enhanced by paracrine signalling from mesenchymal stem cells. J Moll Cell Cardiol 2012, 52:1249-1256.

10. James AW, Levi B, Commons GW, Glotzbach J, Longaker MT: Paracrine interaction between adipose-derived mesenchymal cells. Plast Recontr Surg 2010, 126:806-821. 
11. Mirotsou M, Jayawardena TM, Schmeckpeper J, Gnecchi M, Dzau VJ: Paracrine mechanisms of stem cell reparative and regenerative actions in the heart J Mol Cell Cardiol 2011, 50:280-289.

12. Kawamoto A, Tkebuchava T, Yamaguchi J, Nishimura H, Yoon YS, Milliken C: Intramyocardial transplantation of autologous endothelial progenitor cells for therapeutic neovascularisation of myocardial ischemia. Circulation 2003 , 107:461-468.

13. Beltrami AP, Barlucchi L, Torella D, Baker M, Limana F, Chimenti S, Kasahara H, Rota M, Musso E, Urbanek K, Leri A, Kajstura J, Nadal-Ginard B, Anversa P: Adult cardiac stem cells are multipotent and support myocardial regeneration. Cell 2003, 114:763-776

14. Shiels PG, Maclntyre A, Chen D, Dorling A, Deardon D, Subrimaniam M: IV administration of adult stem cells mitigates STZ induced diabetes in a xenotransplant model. American J Transplant 2005, 5:369.

15. Stevenson KS, McGlynn L, Hoghe M, McLinden H, George WD, Davies RW, Shiels PG: Isolation, characterization and differentiation of Thy1.1-sorted pancreatic adult progenitor cell populations. Stem Cells Dev 2009, 18:1389-1398

16. Stevenson $\mathrm{K}$, Chen D, Maclntyre A, McGlynn LM, Montague $P$, Charif $R$ Subramaniam M, George WD, Payne AP, Davies RW, Dorling A, Shiels PG: Pancreatic-derived Pathfinder cells enable regeneration of critically damaged adult pancreatic tissue and completely reverse streptozotocin-induced diabetes. Rejuv Res 2011, 14:163-171.

17. McGlynn LM, Eller K, MacDonald A, Macintyre A, Russel D, Koppelstaetter C, Davies RW, Shiels PG: Pathfinder cells provide a novel therapeutic intervention for acute kidney injury. Rejuv Res 2013, 16:11-20.

18. Orlic D, Kajstura J, Chimenti S, Jakoniuk I, Anderson SM, Li B, Pickel J, McKay R, Nadal-Ginard B, Bodine DM, Leri A, Anversa P: Bone marrow cells regenerate infarcted myocardium. Nature 2001, 410:701-705.

19. Kajstura J, Marcello R, Whang B, Cascapera S, Hosoda T, Bearzi C, Nursynska D, Kasahara H, Zias E, Bonafé M, Nadal-Ginard B, Torella D, Nascimbene A, Quaini F, Urbanek K, Leri A, Anversa P: Bone marrow cells differentiate in cardiac cell lineages after infarction independently of cell fusion. Circ Res 2005, 96:127-137.

20. Terada N, Hamazaki T, Oka M, Hoki M, Mastalerz DM, Nakano Y, Meyer EM, Morel L, Petersen BE, Scott EW: Bone marrow cells adopt the phenotype of other cells by spontaneous cell fusion. Nature 2002, 416:542-545.

21. Nygren JM, Jovinge S, Breitback $M$, Säwén $P$, Röll W, Hescheler J, Taneera J, Fleischmann BK, Jacobsen SEW: Bone marrow-derived hematopoietic cells generate cardiomyocytes at a low frequency through cell fusion, but not transdifferentiation. Nature Med 2004, 10:494-501.

22. Przybyt E, Krenning G, Brinker MGL, Harmsen C: Adipose stromal cells primed with hypoxia and inflammation enhance cardiomyocyte proliferation rate in vitro through STAT3 and Erk1/2. J Transl Med 2013, 11:39.

23. Burchfield JS, Dimmeler S: Role of paracrine factors in stem and progenitor cell mediated cardiac repair and tissue fibrosis. Fibrogen Tissue Repair 2008, 1:4.

24. Liu J, Narsinh KH, Lan F, Wang L, Nguyen PK, Hu S, Lee A, Han L, Gong Y, Huang M, Nag D, Rosenberg J, Chouldechova A, Robbins RC, Wu JC: Early stem cell engraftment predicts late cardiac functional recovery. Circ Cardiovasc Imaging 2012, 5:481-490.

25. Xiang M, He A, Wang J, Gui C: Protective paracrine effect of mesenchymal stem cells on cardiomyocytes. J Zhejiang Univ Sci B 2009, 10:619-624

26. Luan Y, Zhang X, Kong F, Cheng GH, Qi TG, Zhang ZH: Mesenchymal stem cell prevention of vascular remodelling in high flow-induced pulmonary hypertension through a paracrine mechanism. Int Immunopharmacol 2012 14:432-437.

27. Eulalio A, Mano M, Dal Ferro M, Zentilin L, Sinagra G, Zacchigna S, Giacca M: Functional screening identifies miRNAs inducing cardiac regeneration. Nature 2012, 492:376-381.

28. He L, Hannon GJ: MicroRNAs: small RNAs with a big role in gene regulation. Nat Rev Genet 2004, 5:522-531.

29. Cantaluppi V, Biancone L, Quercia A, Deregibus MC, Segoloni G, Camussi G: Rationale of mesenchymal stem cell therapy in kidney injury. Am J Kidney Dis 2013, 61:300-309.

30. Tögel F, Hu Z, Weiss K, Isaac J, Lange C, Westenfelder C: Administered mesenchymal stem cells protect against ischemic acute renal failure through differentiation-independent mechanisms. Am J Physiol Renal Physiol 2005, 289:F31-F42.
31. Chen L, Tredget EE, Wu PYG, Wu Y: Paracrine factors of mesenchymal stem cells recruit macrophages and endothelial lineage cells and enhance wound healing. PLOS One 2008, 3:e1886.

32. Jackson WM, Nesti $\sqcup$, Tuan RS: Concise review: Clinical translation of wound healing therapies based on mesenchymal stem cells. Stem Cell Trans Med 2012, 1:44-50.

33. Barcelos LS, Duplaa C, Kränkel N, Graiani G, Invercini G, Katare R, Siragusa M, Meloni M, Campesi I, Monica M, Simm A, Campagnolo P, Mangialardi G, Stevanato L, Alessandri G, Emanueli C, Madeddu P: Human CD133 ${ }^{+}$ progenitor cells promote the healing of diabetic ischemic ulcers by paracrine stimulation of angiogenesis and activation of Wnt signalling. Circ Res 2009, 104:1095-1102.

34. Lee SH, Jin SY, Song JS, Seo KK, Cho KH: Paracrine effects of adipose-derived stem cells on keratinocytes and dermal fibroblasts. Ann Dermatol 2012, 24:136-143.

35. Quertainmont R, Cantinieaux D, Botman O, Eid S, Schoenen J, Franzen R: Mesenchymal stem cell graft improves recovery after spinal cord injury in adult rats through neurotrophic and pro-angiogenic actions. PLoS One 2012, 7:e39500.

36. Wright KT, Masri WE, Osman A, Chowdhury J, Johnson WEB: Concise review: bone marrow for the treatment of spinal cord injury: mechanisms and clinical implications. Stem Cells 2011, 29:169-178.

37. Eggenhofer E, Hoogduijn MJ: Mesenchymal stem cell-educated macrophages. Transplant Res 2012, 1:12

38. Cocucci E, Rachetti G, Meldolesi J: Shedding microvesicles: artefacts no more. Trends Cell Biol 2009, 19:43-51.

39. Lee Y, Andaloussi SEL, Wood MJA: Exosomes and microvesicles: extracellular vesicles for genetic information transfer and gene therapy. Hum Mol Genet 2012, 21:R125-R134.

40. Fleissner F, Goerzig Y, Haverich A, Thum T: Microvesicles as a novel biomarkers and therapeutic targets in transplantation medicine. Am J Transplant 2012, 12:289-297.

41. Ohno S, Ishikawa A, Kuroda M: Roles of exosomes and microvesicles in disease pathogenesis. Adv Drug Deliv Rev 2013, 65:398-401.

42. Dragovic RA, Gardiner C, Brooks AS, Tannetta DS, Ferguson DJP, Hole P, Carr B, Redman CWG, Harris AL, Dobson PJ, Harrison P, Sargent IL: Sizing and phenotyping of cellular vesicles using Nanoparticle Tracking Analysis. Nanomed 2011, 7:780-788.

43. Muralidharan-Chari V, Clancy JW, Sedgwick A, D'Souza-Schorey C: Microvesicles: mediators of extracellular communication during cancer progression. J Cell Sci 2010, 123:1603-1611.

44. Akers JC, Gonda D, Kim R, Carter BS, Chen CC: Biogenesis of extracellular vesicles (EV): exosomes, microvesicles, retrovirus-like vesicles, and apoptotic bodies. J Neurooncol 2013, 113:1-11.

45. Bruno S, Grange C, Deregibus MC, Calogero RA, Saviozzi S, Collino F, Morando L, Busca A, Falda M, Bussolati B, Tetta C, Camussi G: Mesenchymal stem cell-derived microvesicles protect against acute tubular injury. J Am Soc Nephrol 2009, 20:1053-1067.

46. Cantaluppi V, Gatti S, Medica D, Figliolini F, Bruno S, Deregibus MC, Sordi A, Biancone L, Tetta C, Camussi G: Microvesicles derived from endothelial progenitor cells protect the kidney from ischemiareperfusion injury by microRNA-dependent reprogramming of resident renal cells. Kidney Int 2012, 82:412-427.

47. Gatti S, Bruno S, Deregibus MC, Sordi A, Cantaluppi V, Tetta C, Camussi $\mathrm{G}$ : Microvesicles derived from human adult mesenchymal stem cells protect against ischaemic-reperfusion-induced acute and chronic kidney injury. Nephrol Dial Transplant 2011, 26:1474-1483.

48. Herrera MB, Fonsato V, Gatti S, Deregibus MC, Sordi A, Cantarella D Calogero R, Bussolati B, Tetta C, Camussi G: Human liver stem cell-derived microvesicles accelerate hepatic regeneration in hepatectomized rats. J Cell Mol Med 2010, 14:1605-1618.

49. Zhang HC, Liu XB, Huang $S$, Bi XY, Wang HX, Xie LX, Wang YQ, Cao XF, LV J, Xiao FJ, Yang Y, Guo ZK: Microvesicles derived from human umbilical cord mesenchymal stem cells stimulated by hypoxia promote angiogenesis both in vitro and in vivo. Stem Cell Dev 2012, 21:3289-3297.

50. Lee C, Mitsialis SA, Aslam M, Vitali SH, Vergadi E, Konstantinou G, Sdrimas K, Fernandez-Gonzalez A, Kourembanas S: Exosomes mediate the cytoprotective action of mesenchymal stromal cells on hypoxia-induced pulmonary hypertension. Circulation 2012, 26:2601-2611. 
51. Zuo S, Jones WK, Li H, He Z, Pasha Z, Yang Y, Wang Y, Fan GC, Ashraf M, Xu M: Paracrine effect of Wnt11 overexpressing mesenchymal stem cells on ischemic injury. Stem Cells Dev 2012, 21:598-608.

52. Gnecchi M, He H, Liang OD, Melo LG, Morello F, Mu H, Noiseux N, Zhang L, Pratt RE, Ingwall JS, Dzau VJ: Paracrine action accounts for marked protection of ischemic heart by Akt-modified mesenchymal stem cells. Nat Med 2005, 11:367-368.

53. Iglesias DM, El-Kares R, Taranta A, Bellomo F, Emma F, Besouw M, Levtchenko E, Toelen J, van den Heuvel L, Chu LL, Zhao J, Young YK, Eliopoulos N, Goodyer P: Stem cell microvesicles transfer cystinosin to human cystinotic cells and reduce cysteine accumulation in vitro. PLoS One 2012, 7:e42840.

54. Ratajczak MZ, Kucia M, Jadczyk T, Greco NJ, Wojakowski W, Tendera M, Ratajczak J: Pivotal role of paracrine effects in stem cell therapies in regenerative medicine: can we translate stem cell-secreted paracrine factors and microvesicles into better therapeutic strategies? Leukemia 2012, 26:1166-1173.

55. Makkar RR, Smith RR, Cheng K, Malliaras K, Thomson LEJ, Berman D, Czer LSC, Marbán L, Mendizabal A, Johnston PV, Russell SD, Schuleri KH, Lardo AC, Gerstenblith G, Marbán E: Intracoronary cardiosphere-derived cells for heart regeneration after myocardial infarction (CADUCEUS): a prospective, randomised phase 1 trial. Lancet 2012, 379:895-904.

56. Bolli R, Chugh AR, D'Amario D, Loughran JH, Stoddard MF, Ikram S, Beache GM, Wagner SG, Leri A, Hosoda T, Sanada F, Elmore JB, Goichberg P, Cappetta D, Solankhi NK, Fahsah I, Rokosh DG, Slaughter MS, Kajstura J, Anversa P: Cardiac stem cells in patients with ischaemic cardiomyopathy (SCIPIO): initial results of a randomised phase 1 trial. Lancet 2011, 378:1847-1857.

doi:10.1186/2047-1440-2-10

Cite this article as: Anthony and Shiels: Exploiting paracrine mechanisms of tissue regeneration to repair damaged organs. Transplantation

Research 2013 2:10.

\section{Submit your next manuscript to BioMed Central and take full advantage of:}

- Convenient online submission

- Thorough peer review

- No space constraints or color figure charges

- Immediate publication on acceptance

- Inclusion in PubMed, CAS, Scopus and Google Scholar

- Research which is freely available for redistribution 